\title{
Research on Effects of Solvents on Propylene Epoxidation with the TS-1
}

\author{
Catalyst \\ Lina Wang ${ }^{1, \text { a }}$ \\ ${ }^{1}$ Xi an University of Science and Technology, Xi'an, Shaanxi, China, 710054 \\ ${ }^{\mathrm{a}}$ email
}

Keywords: TS-1, Propylene Epoxidation, Solvent Effects, Catalyst

\begin{abstract}
Solvents have an important effect on the epoxidation of propylene catalyzed by TS-1. Through the experiment, this paper analyzes the effects of concentration of $\mathrm{H}_{2} \mathrm{O}_{2}$ and the addition of methanol in small amount on the propylene conversion, $\mathrm{PO}$ selectivity and $\mathrm{H}_{2} \mathrm{O}_{2}$ utilization in order to provide some references for the relative researchers.
\end{abstract}

\section{Introduction}

Propylene oxide (PO) is an important organic chemical raw material. We usually adopt the methods of chlorine alcohol or Halcon in the industrial production of PO. These two methods have the problems of pollution and co-production respectively. Taramasso synthesized titanium containing molecular sieve with the TS-1catalyst for the first time in 1983. With hydrogen peroxide as the oxidant, the titanium silicate molecular sieve has a unique selective oxidation performance for olefin, alcohol and alkyl chain. Titanium silicon molecular sieve catalytic epoxidation of propylene to produce propylene oxide compared with the traditional production method, has no corrosion, not associated with a large number of organic productions, mild reaction conditions, friendly to environment and provides a new way for the production of propylene oxide. In the epoxidation of olefins with $\mathrm{H}_{2} \mathrm{O}_{2}$ as catalyst and TS-1 as oxidant, the property of solvent has a significant influence on the reaction performance. The solvent influences the formation of the reaction transition state, which influences the reaction activity, product distribution and the effective utilization of the oxidant. In methanol and other solvents, propylene catalyzed by TS-1 and other low carbon alkene epoxidation activity, Clerici proposed five membered ring transition state mechanism to explain. The coordination of $\mathrm{ROH}$ molecule with the titanium peroxide $\mathrm{TiOOH}$ forms a stable five element ring structure, which increases the stability of the titanium peroxide and the affinity of the oxygen atom, so that the oxygen atom is easy to adsorb the rich propylene. The epoxidation of propylene in the proton solvent has a higher reaction activity, but it is easy to have an open loop reaction with PO because of the active hydrogen atom, which leads to the decrease of the selectivity of the target product. Therefore, it is valuable to find more suitable solvent for the reaction. Therefore, despite the importance of the solvent effect on the catalytic reaction has been most TS-1 knowledge, but most studies only from one aspect of several solvents activity were also investigated and explained, and the lack of solvent effect on TS- $1 / \mathrm{H}_{2} \mathrm{O}_{2}$ which is a special catalytic oxidation system for in-depth and comprehensive analysis. Starting from the reaction mechanism, this paper analyzes the effects of solvents on propylene epoxidation with the ts-1 catalyst through the experiment to lay a foundation for further industrialization of PO green chemical clean production process. 


\section{Experiment}

TS-1 was firstly synthesized in the experiment, the particle size of which is $0.1 \sim 0.3 \mathrm{um}$. The $\mathrm{H}_{2} \mathrm{O}_{2}$ solution is industrial product and the mass fraction is $30 \%$. The propylene concentration is higher than $99.5 \%$. The epoxidation of propylene was carried out in a $120 \mathrm{~mL}$ stainless steel reaction vessel, and the semi continuous operation mode, namely, the propylene continuous reactor, the liquid phase reactant and catalyst remain in the reactor. When the reaction time, the solvent, the mass fraction of $30 \% \mathrm{H}_{2} \mathrm{O}_{2}$, the chromatographic internal standard methyl tert butyl ether (MTBE) and the catalyst TS-1 into the reaction kettle, the temperature of the material to be raised to the reaction temperature, the reaction temperature is passed into the propylene, and the reaction is started. Pressure from the cylinder of the propylene to the reaction system after the pressure required to enter the reactor, the reaction system pressure from the reactor outlet regulator valve adjustment. The reaction kettle in a constant temperature water bath, the propylene epoxidation is a highly exothermic reaction. The cooling water pipe reactor is necessary to keep the temperature constant and the temperature error is plus or minus $0.5{ }^{\circ} \mathrm{C}$. Oxidation of solvent alcohol side reaction, the TS-1 catalyst, solvent and added to the reactor chromatography internal standard MTBE, the required temperature to a constant temperature water bath heating, pass into the $\mathrm{H}_{2} \mathrm{O}_{2}$ reaction, through the $\mathrm{N}_{2}$ to maintain a certain pressure, regular sampling analysis. PO open loop side reaction: first the mass fraction of alcohol solvent, $30 \% \mathrm{H}_{2} \mathrm{O}_{2}$, MTBE and TS- 1 are added into the reactor. When the temperature heated by the water bath reached the required value, we added the PO into the reaction and did the sampling analysis. The experimental devices are shown in Figure 1.

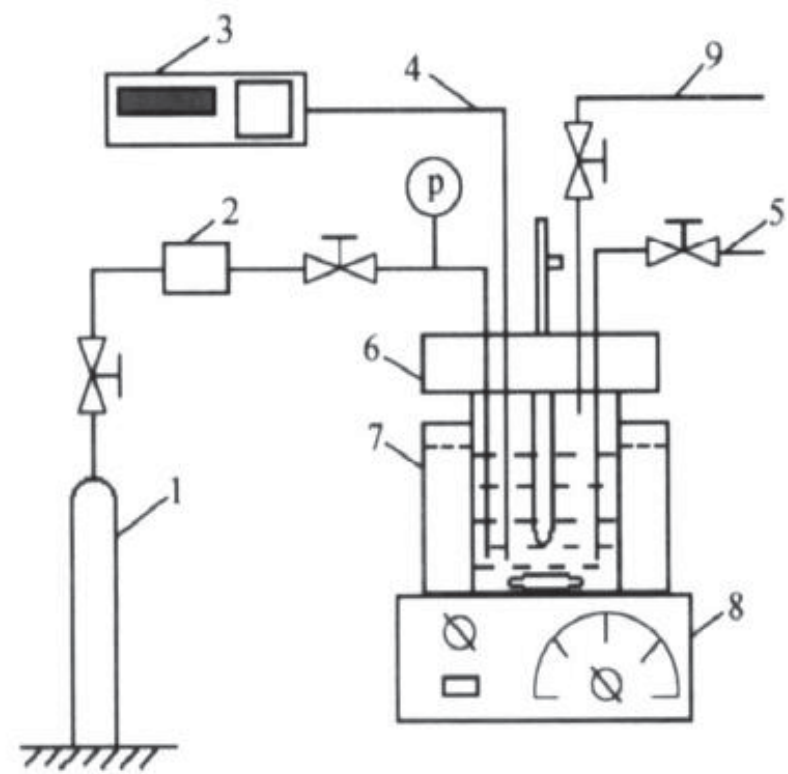

Figure 1.Figure of experimental devices

In the Figure 1, 1 represents propylene cylinder; 2 represents pressure reducing valve; 3 represents temperature display; 4 represents thermocouples; 5 represents sampling outlets; 6 represents stainless steel reactor; 7 represents constant temperature water tank; 8 represents magnetic mixer; 9 represents exhaust gas outlets.

\section{Effects of Solvents on Propylene Epoxidation with the TS-1 Catalyst}

Effects of Concentration of $\mathbf{H}_{2} \mathbf{O}_{2}$. This section examines the raw $\mathrm{H}_{2} \mathrm{O}_{2}$ concentration (different $\mathrm{H}_{2} \mathrm{O}_{2}$ space velocity: $0.63 \mathrm{~h}^{-1}, 0.46 \mathrm{~h}^{-1}, 0.31 \mathrm{~h}^{-1}$ ) effects on the epoxidation reaction. As the Figure 2 to Figure 4 show, when the $\mathrm{H}_{2} \mathrm{O}_{2}$ concentration is $30 \mathrm{wt} \%$, the conversion of propylene, 
PO selectivity and the effective use of the highest $\mathrm{H}_{2} \mathrm{O}_{2}$. When the concentration of $\mathrm{H}_{2} \mathrm{O}_{2}$ decreased, the three indexes all decreased, and the catalyst was deactivated. There are two main reasons, one is the concentration of $\mathrm{H} 202$ is low, the water content is high, the catalyst bed flooded the greater the possibility of the effect is worse; on the other hand, under the same feeding airspeed $\mathrm{H}_{2} \mathrm{O}_{2}$ solution, the lower the speed is, the less $\mathrm{H}_{2} \mathrm{O}_{2}$ participated in the reaction is.

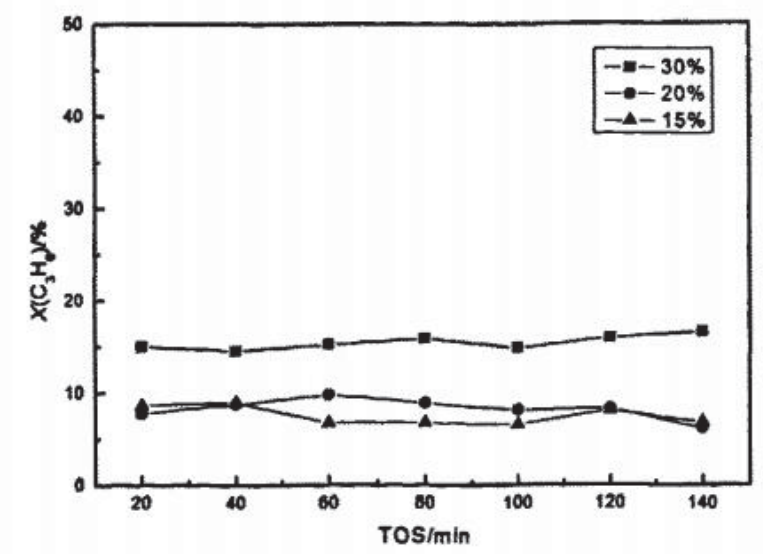

Figure2. Effect of the concentration of $\mathrm{H}_{2} \mathrm{O}_{2}$ on propylene conversion

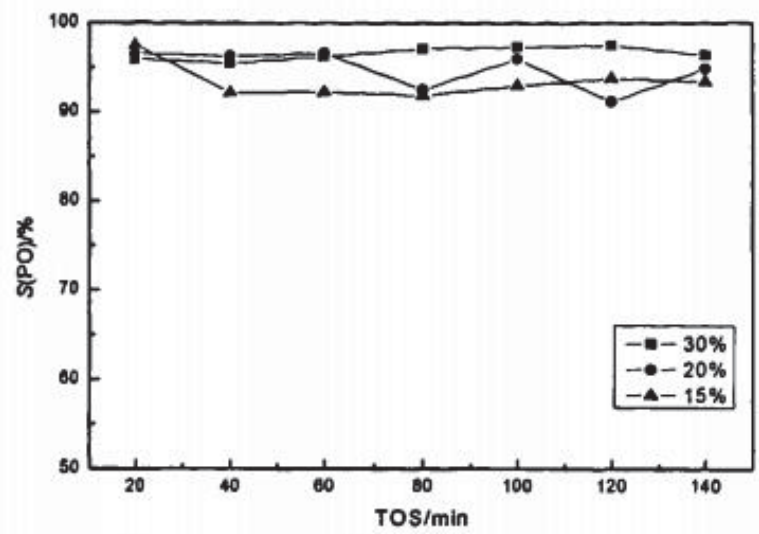

Figure 3.Effect of the concentration of $\mathrm{H}_{2} \mathrm{O}_{2}$ on PO selectivity

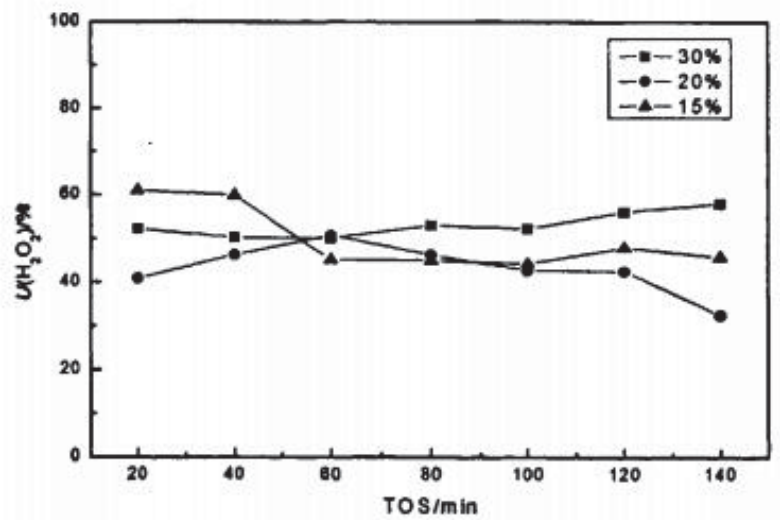

Figure 4.Effect of the concentration of $\mathrm{H}_{2} \mathrm{O}_{2}$ on $\mathrm{H}_{2} \mathrm{O}_{2}$ utilization

Effects of Addition of Methanol in Small Amount. We use the TS-1 molecular sieve as catalyst and the $\mathrm{H}_{2} \mathrm{O}_{2}$ as the oxidation agent of the propylene liquid phase epoxidation. When it has the highest catalytic activity, the use of other organic solvents or water as solvent the reaction efficiency is greatly reduced. Therefore, this section examines the addition of methanol (introduced methanol steam to TS-1 catalyst bed is in the raw material propylene into the reactor before 
methanol tank bubbling, methanol tank temperature is maintained at $20{ }^{\circ} \mathrm{C}$ ) effect on propylene epoxidation performance. The reaction results were shown in Figure 5 to Figure 7 . When the reaction process without adding methanol, propylene conversion rate of $15 \%$, while adding a small amount of methanol in the reaction process (mole ratio of propylene and methanol is about 10) the effective use of propylene conversion, the selectivity of $\mathrm{PO}$ and $\mathrm{H}_{2} \mathrm{O}_{2}$ decrease rate. The experimental results show that the addition of a small amount of methanol is not as beneficial as the liquid phase epoxidation of propylene. So it is not added in the epoxidation system of propylene gas phase.

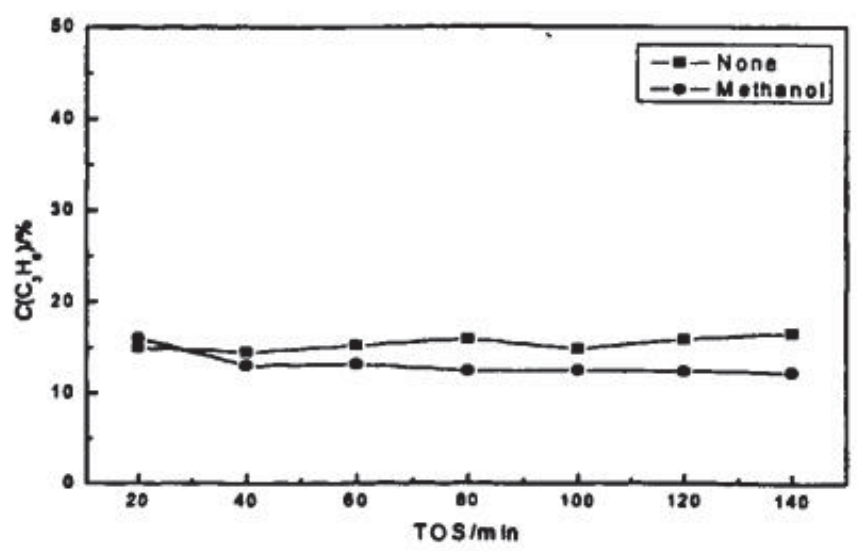

Figure 5.Effect of addition of methanol in small amount on propylene conversion

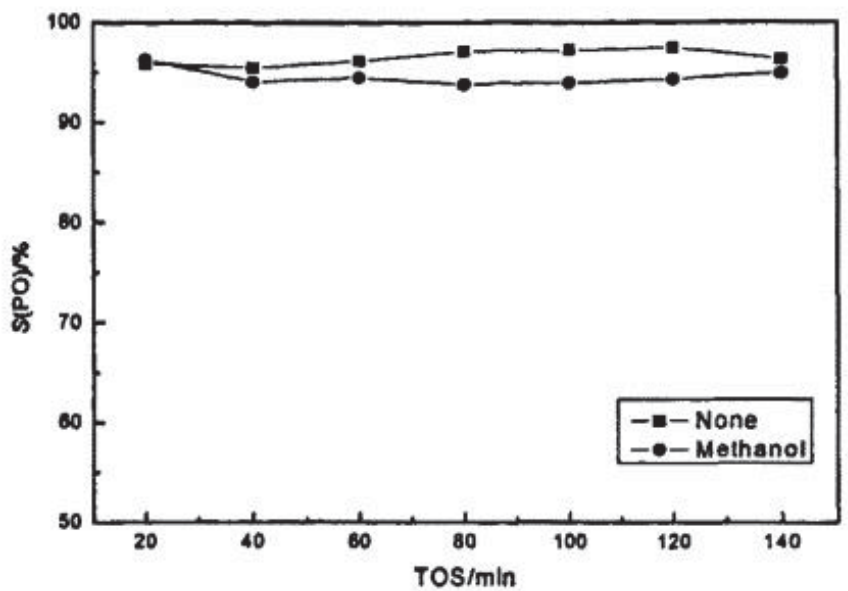

Figure 6.Effect of addition of methanol in small amount on PO selectivity

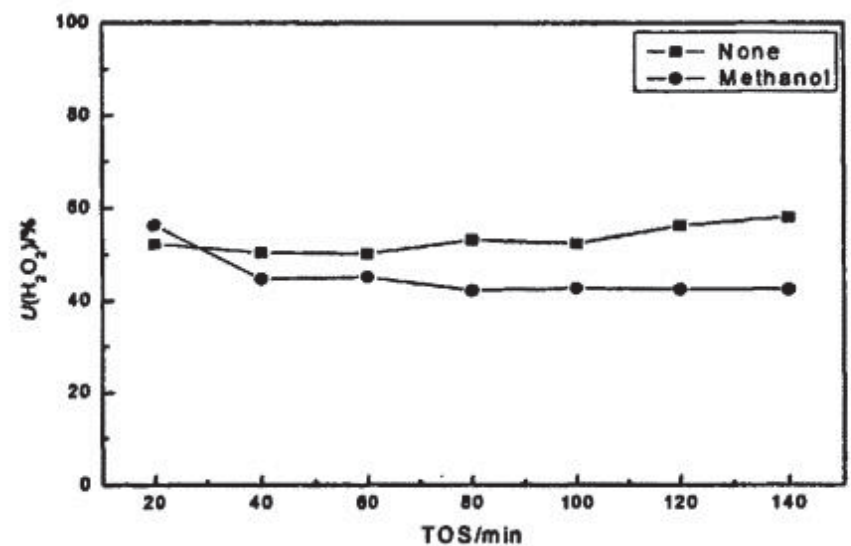

Figure7. Effect of addition of methanol in small amount on $\mathrm{H}_{2} \mathrm{O}_{2}$ utilization 


\section{Conclusion}

Under the optimum conditions of propylene epoxidation, the conversion of propylene was about $15 \%$. Simultaneously, the selectivity of $\mathrm{PO}$ was over $95 \%$, and the effective utilization rate of $\mathrm{H}_{2} \mathrm{O}_{2}$ was close to $60 \%$. Under the appropriate conditions, namely the propylene space velocity of $2.81 \mathrm{~h}^{-1}$, PO space time yield can reach $559 \mathrm{mg} \mathrm{POh}^{-1}$ (goat) ${ }^{-1}$. In propylene gas phase reaction conditions, appropriate reduction of non-framework titanium in TS-1, increasing the reaction temperature and the propylene feed amount can significantly improve the performance of the catalyst epoxidation to improve the effective utilization rate of hydrogen peroxide. Reducing the non-framework titanium can obviously reduce the decomposition of hydrogen peroxide. The appropriate increasing in temperature and the propylene feed is more favorable to the oxidation of central competitive reaction.

\section{Acknowledgements}

This research was financially supported by Youth Fund of National Natural Science Foundation (Grant No. 21506170).

\section{References}

[1] Xiong Yong, Zhang Yu, Liu Yi, Du Zexue, Chemical Industry and Engineering Progress, Vol. 25(2006) No 6, p.675-679

[2] Wu Yulong, Liu Qingshan, Su Xueli, Mi Zhentao, Journal of Tsinghua University (Science and Technology), Vol. 47(2007) No 9, p.1511-1515

[3] Meng Jiwen, Li Gang, Wang Xiangsheng, Guo Xinwen, Liu Xuewu, Journal of Molecular Catalysis (China), Vol. 17(2003) No 2, p.106-110

[4] Meng Jiwen, Li Gang, Wang Xiangsheng, Guo Xinwen, Journal of Dalian University of Technology, Vol. 43(2003) No 5, p.577-581 